\title{
Estudo de dimensionamento de pavimento flexível da avenida principal de acesso ao parque industrial de Porto Nacional/TO
}

A implantação de indústrias de tecnologia de ponta demanda uma infraestrutura de qualidade, que proporcione um sistema logístico de transportes que garanta as condições necessárias de escoamento de tráfego. $O$ estímulo às instalações de grandes empreendimentos, tem sua atratividade impulsionada, não apenas pelas políticas de incentivos fiscais, mas também pela localização estratégica, atrelada a uma estrutura eficiente, que garanta uma qualidade de escoamento de matériaprima e/ou produto final. No Brasil o principal modo de transportes de cargas e passageiros é o rodoviário, com isso, é imprescindível que o projeto, bem como a execução dos pavimentos, seja realizado com estudos e técnicas adequadas. Os pavimentos flexíveis, possuem requisitos técnicos que precisam ser atendidos para a sua eficácia. Este estudo tem como objetivo principal, realizar um estudo de adequação sobre a infraestrutura do Parque Industrial de Porto Nacional/TO, onde, pretende-se fazer o levantamento do tráfego e propor o dimensionamento do pavimento para a Avenida Principal, que por sua vez não é asfaltada em conformidade ao tráfego ocasionado pelo escoamento de produtos e comodities, oriundos de empreendimentos locais.

Palavras-chave: Parque Industrial; Estudo de Tráfego; Pavimentos flexíveis.

\section{Flexible floor dimensioning study of main avenue access to Porto National/TO industrial park}

\begin{abstract}
The deployment of high-tech industries requires quality infrastructure that provides a logistics transportation system that ensures the necessary conditions for traffic flow. The incentive to the installations of large enterprises, has its attractiveness driven, not only by the tax incentive policies, but also by the strategic location, linked to an efficient structure, which guarantees the quality of raw material and/or final product flow. In Brazil the main mode of transportation of cargo and passengers is by road, so it is essential that the project, as well as the execution of pavements, be carried out with appropriate studies and techniques. Flexible floors have technical requirements that need to be met for their effectiveness. The main objective of this study is to carry out a suitability study on the infrastructure of the Industrial Park of Porto Nacional/TO, where it is intended to survey the traffic and propose the sizing of the pavement for Avenida Principal, which in turn does not It is paved in accordance with traffic caused by the flow of products and commodities from local enterprises.
\end{abstract}

Keywords: Industrial Park; Traffic Study; Flexible Floors.

Topic: Engenharia de Transportes

Reviewed anonymously in the process of blind peer.
Received: 12/08/2019

Approved: 22/11/2019
Max Rodrigo Brito dos Santos

Instituto Tocantinense Presidente Antônio Carlos, Brasil http://lattes.cnpq.br/1547014161028868

maxrodrigo 15@hotmail.com

\section{Flávio Vieira da Silva Júnior}

Instituto Tocantinense Presidente Antônio Carlos, Brasil

http://lattes.cnpq.br/2211436659738090

flaviovisiju@gmail.com

Alesi Teixeira Mendes

Instituto Tocantinense Presidente Antônio Carlos, Brasil

http://lattes.cnpq.br/2473113080999082

http://orcid.org/0000-0002-5632-7235

alesitmendes@gmail.com
Referencing this:

SANTOS, M. R. B.; SILVA JÚNIOR, F. V.; MENDES, A. T.. Estudo de dimensionamento de pavimento flexível da avenida principal de acesso ao parque industrial de Porto Nacional/TO. Engineering Sciences, v.7, n.3, p.84-95, 2019. DOI: http://doi.org/10.6008/CBPC2318-3055.2019.003.0008 


\section{INTRODUÇÃO}

A implantação de indústrias de tecnologia de ponta demanda uma infraestrutura de qualidade, que proporcione um sistema logístico de transportes que garanta as condições necessárias de escoamento de tráfego. No Brasil, tratativas que facilitam a abertura e funcionamento de distritos industriais estão em ascensão. São propostos programas que possam beneficiar empresas, como políticas de incentivos fiscais, contudo, esses empreendimentos precisam de estudos de viabilidade e mercado, tráfego, entre outros que afetam diretamente a comunidade em sua circunscrição (PORTER, 1989).

Em detrimento ao elevado tráfego de veículos pesados, responsáveis pelo transporte das cargas, exige das estradas resistência e desempenho adequado. Uma estrutura de pavimento eficiente tornou-se um estudo de grande importância a engenharia de transportes, pelo seu impacto direto no cotidiano dos cidadãos residentes em suas proximidades. A questão não é apenas o deslocamento entre pontos, mas ser eficientemente capaz de realizá-lo com segurança e qualidade.

A execução de um projeto com alterações técnicas de infraestrutura, visa a melhoria logística, resultando na atratividade a novos empreendimentos, tema a ser abordado neste trabalho. O objetivo deste trabalho é realizar um estudo sobre a infraestrutura do Parque Industrial de Porto Nacional - TO, onde, pretende-se fazer o levantamento do tráfego e propor o dimensionamento do pavimento para a Avenida Principal, que por sua vez não é asfaltada em conformidade ao tráfego ocasionado pelo escoamento de produtos e comodities, oriundos de empreendimentos locais.

\section{METODOLOGIA}

\section{Área de estudo}

Para o desenvolvimento do projeto de pesquisa e atingir o objetivo do estudo, foi escolhido a extensão de 2,8 Km da Avenida Principal do Parque Industrial de Porto Nacional - TO (Figura 1), que tem seu acesso às margens da TO-050. O loteamento de 322,7440ha com mais de 500 lotes em 31 quadras, está estrategicamente posicionado numa região considerada como um polo do agronegócio na região norte do Brasil. Os seguimentos industriais instalados são compostos por produção de biodiesel e farelo de soja, em grande escala, pré-moldados, cerâmica e uma indústria de cerveja artesanal.

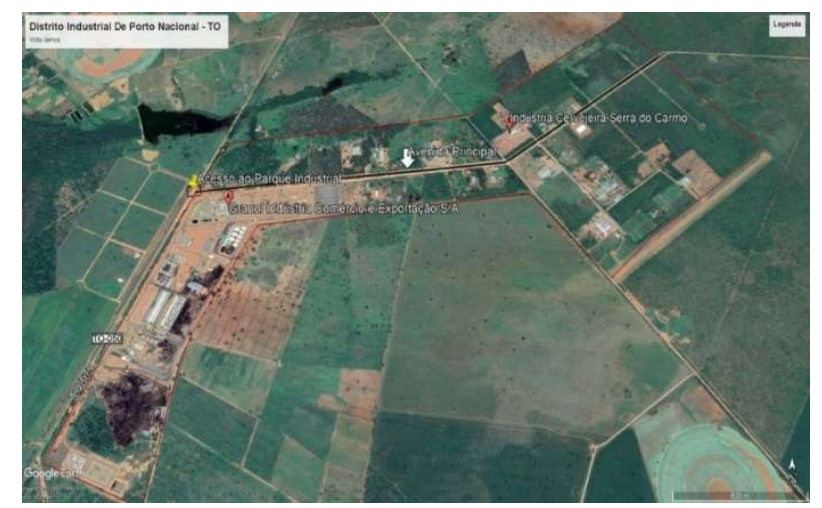

Figura 1: Parque Industrial de Porto Nacional/TO. 
As etapas para a execução dos ensaios, bem como, para a determinação do fluxo de veículos, inicialmente, foram disponibilizados pela empresa de biodiesel, situada na área de estudo, dados referentes ao tráfego de veículos pesados dentro do Parque Industrial, tendo em vista que a mesma ocupa a maior área do distrito e é responsável pelo grande fluxo de veículos de grande porte. Nas visitas em campo foram extraídas, com uso de perfuratriz (Figura 2), amostras do subleito para análise da qualidade do material utilizado por meio do ensaio de CBR - Califórnia Bearing Ratio, a amostra do subleito foi extraída a uma profundidade média de 2,50 m da superfície para o ensaio mecânica mencionado anteriormente e os ensaios de Limite de Plasticidade (WP), Limite de Liquidez (WL), Massa Especifica do Solo, Análise Granulométrica e Compactação.

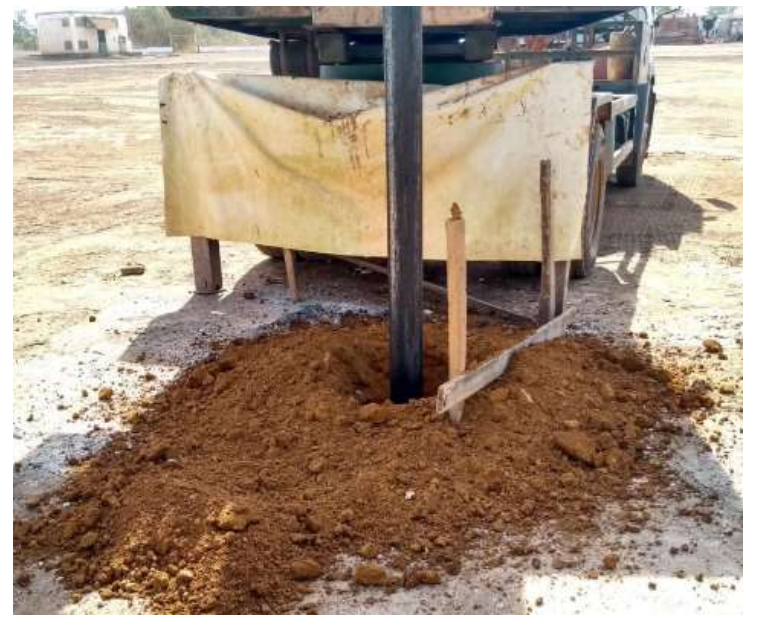

Figura 2: Coleta de amostras do solo.

Todos os ensaios foram realizados no laboratório de Geotecnia e Pavimentação do Instituto Tocantinense Presidente Antônio Carlos, no período de agosto a setembro de 2019. O material foi colocado para secar ao ar livre e posteriormente foi destorroado, conforme figuras 3 e 4, para em seguida ser utilizado na execução dos ensaios que já foram supracitados.

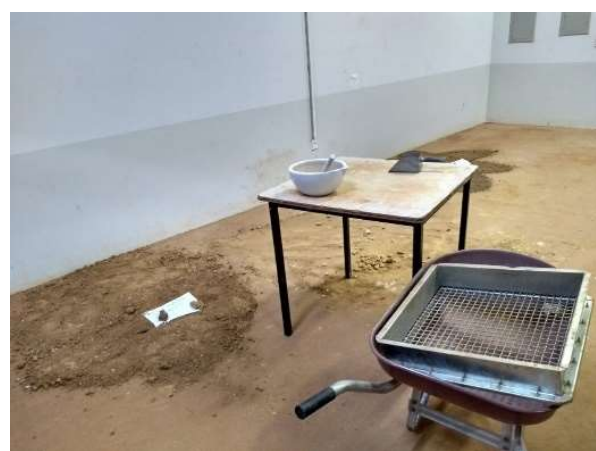

Figura 3: Material coletado.

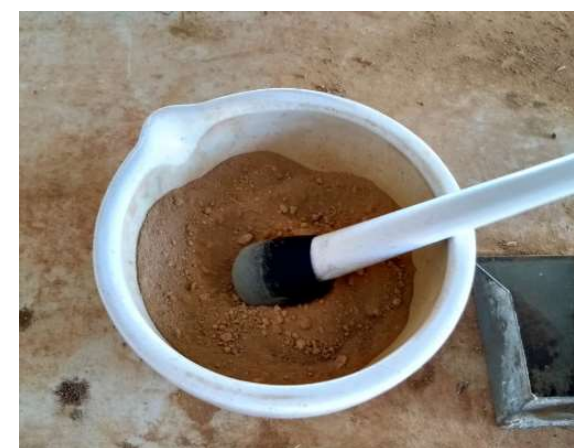

Figura 4: Destorroamento do material.

\section{Ensaios físicos}

A determinação dos Limites de consistência foi separada cerca de $180 \mathrm{~g}$ de material, destorroado e seco ao ar livre, que passa na peneira $40(0,42 \mathrm{~mm})$. Colocou-se parte da amostra no recipiente de porcelana e de forma graduada adicionado água até a homogeneização da massa. Transferiu-se a massa para a concha do aparelho de Casagrande (Figura 5), onde se fez sua divisão em duas. 


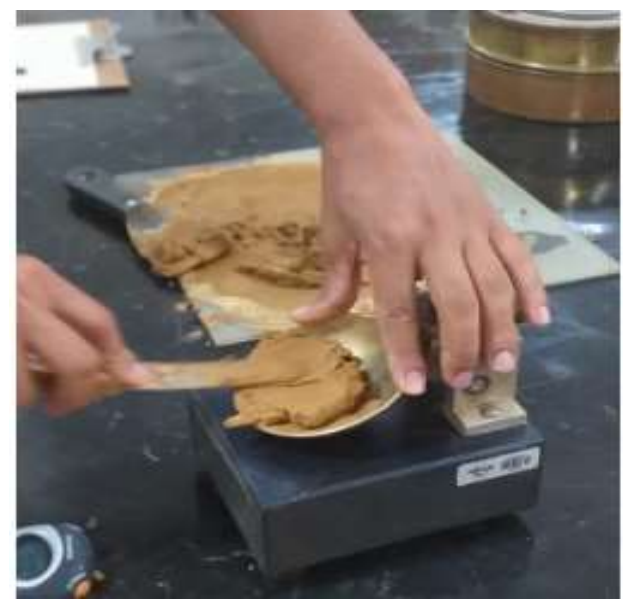

Figura 5: Material em aparelho de Casagrande.

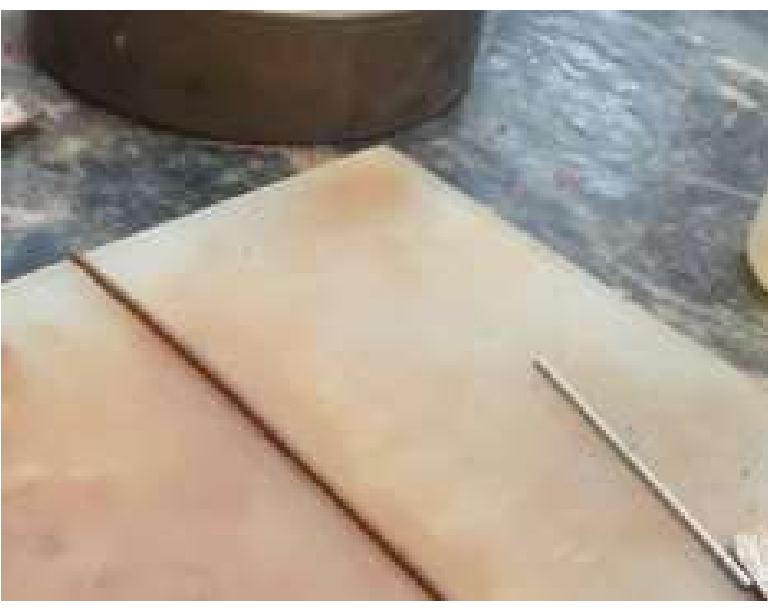

Figura 6: Ensaio Limite de Plasticidade.

O ensaio de Limite de Liquidez foi executado com o objetivo de obter a umidade pela quantidade de golpes que o solo fecha a divisão das partes (ranhura), ou seja, passa pelo ponto de transição entre o estado plástico para o líquido. O procedimento de ensaio foi feito segundo a norma da Associação Brasileira de Normas Técnicas (ABNT), a NBR 7180/1982.

Também foi realizado o ensaio de Limite de Plasticidade, onde foi moldado uma quantidade de $10 \mathrm{~g}$ da massa em forma elipsoidal, como mostra a figura 6, rolando-a em seguida sobre a placa de vidro, até que fissurasse em pequenos fragmentos. Ao se fragmentar o cilindro, com diâmetros de 3 mm e comprimento de $100 \mathrm{~mm}$, este foi transferido para um recipiente adequado com o objetivo de determinar o teor de umidade do solo quando ele passa do estado plástico para o semissólido.

Posteriormente, com o objetivo de classificar o solo de forma granulométrica, realizou-se o ensaio de granulometria por peneiramento com auxílio das peneiras determinadas em conformidade a NBR 7181/1988 como mostra a figura 7. A classificação granulométrica se difere conforme dimensões: Pedregulho: 76 a 4,8 mm; Areia: 4,8 a 0,05 mm; Silte: 0,05 a 0,005 mm; Argila: menor que 0,005 mm.

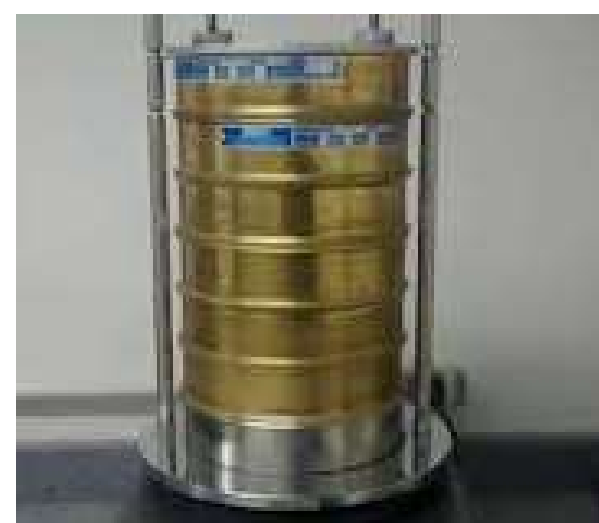

Figura 7: Ensaio de Granulometria.

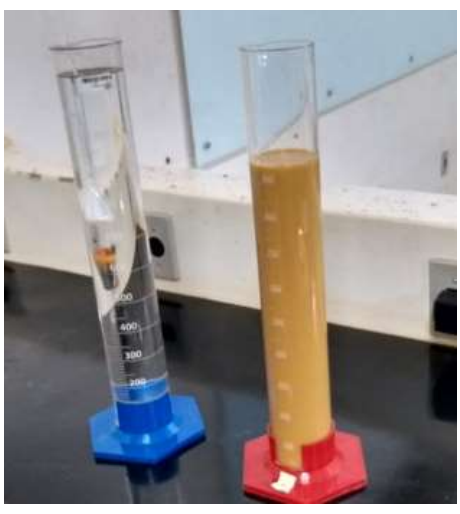

Figura 8: Ensaio de Sedimentação.

Dentre os ensaios realizados, com o objetivo de obter a porcentagem de finos que compõe, foi executado o ensaio de sedimentação, conforme exibe na Figura 8, no qual foi utilizado cerca de $70 \mathrm{~g}$ de solo diante a análise tátil visual que certificou que o material seria argiloso ou siltoso. Posteriormente, realizouse o ensaio de compactação, regida pela norma NBR 7182/1988 na qual foram compactados cinco corpos de 
prova como mostra na Figura 9, com material do subleito, com Energia Proctor intermediária, na umidade ótima e com seu peso específico aparente seco obtido a partir das curvas de compactação.



Figura 9: Corpos de prova do Ensaio de Compactação.

Em conformidade a NBR 6508/1984, foi executado o ensaio de Massa Específica, conforme ilustrado na figura 10. A execução do ensaio juntamente com os ensaios de granulometria e limites de consistência tem por finalidade caracterizar o solo. Para o ensaio de Penetração e Expansão foi necessário consultar a NBR 9895/2017, o processo laboratorial é típico para o dimensionamento de rodovias, que por sua vez é um dos mais validados na avaliação das características dos solos, tanto para o dimensionamento quanto para o comportamento das camadas do pavimento. Inicialmente foi necessário $18 \mathrm{~kg}$ de amostra, sendo utilizado $6 \mathrm{~kg}$ para cada corpo de prova, onde ele foi compactado com 26 golpes (Energia Proctor Normal) para cada uma das 5 camadas. Posteriormente, os corpos de prova foram condicionados a imersão num tanque d'agua por 4 dias, para verificação da expansão. Finalizada as leituras realizadas no extensômetro de 24 em 24 horas e deixando-os escoar a água por um período de $2 \mathrm{~h}$, os corpos de prova estavam aptos ao processo de penetração na prensa, como ilustrado na Figura 11, com finalidade de obtenção do valor de CBR.

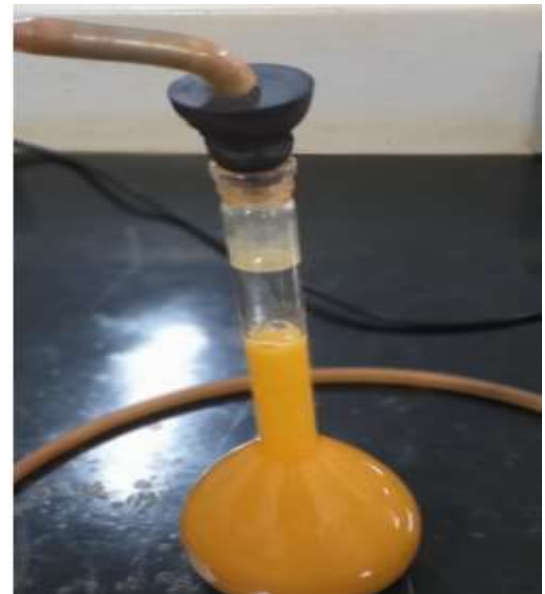

Figura 10: Ensaio de Massa Específica.

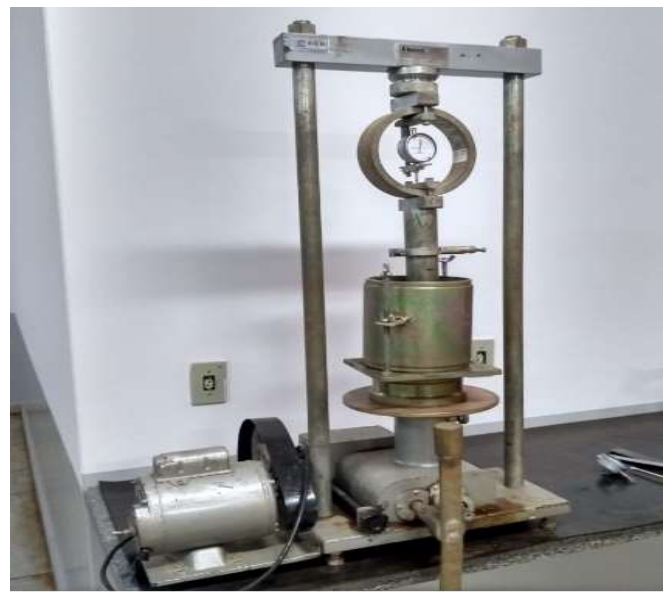

Figura 11: Prensa utilizada em Ensaio de CBR.

\section{RESULTADOS E DISCUSSÃO}

\section{Classificação dos Solos}

A amostra de solo utilizada nos ensaios foi classificada com o auxílio dos parâmetros de análises de limites de consistência, ensaios granulométricos e índice de grupo do subleito, sendo apresentados seus resultados na Tabela 1. Segundo os dados da American Association of State Highway and Transportation 
Officials-AASHTO foi classificado no grupo da família A-4, solos siltosos tendo comportamento geral para o subleito de sofrível a mau. Na classificação Highway Research Bord (HRB), Figura 12, os solos são divididos em grupos e subgrupos, em função da sua granulometria, índices de consistência e índice de grupo demostrados na Tabela 1, com isso o subleito foi classificado como da família silto argilosos e do grupo A-4, solos siltosos.

Tabela 1: Caracterização física para a AASHTO.

\begin{tabular}{|l|l|l|}
\hline DESCRIÇÃO & RESULTADOS & UN.MED. \\
\hline Massa específica & 2,742 & $\mathrm{~g} / \mathrm{cm} 3$ \\
\hline Peneiramento passante na peneira 10 & 100 & $\%$ \\
\hline Peneiramento passante na peneira 40 & 79,1 & $\%$ \\
\hline Peneiramento passante na peneira 200 & 52,9 & $\%$ \\
\hline Limite de liquidez - WL & 29,3 & $\%$ \\
\hline Limite de plasticidade - WP & 21,1 & $\%$ \\
\hline Índice de plasticidade - IP & 8,2 & $\%$ \\
\hline Peso específico seco máximo- ${ }^{\mathbf{P}}$ d máx. & 1,9 & $\mathrm{~g} / \mathrm{cm} 3$ \\
\hline Umidade ótima Wót & 13,2 & $\%$ \\
\hline
\end{tabular}

Em conformidade a classificação pelo Sistema Unificado de Classificação dos Solos-SUCS, foram aplicados os dados dos ensaios, tendo em vista que o mesmo se baseia na qualidade da textura e plasticidade do material, sendo necessário aplicar a análise granulométrica e índice de consistência, com os resultados das porcentagens que passam nas peneiras como mostra a Tabela 2, obteve-se os coeficientes de uniformidade e coeficiente de curvatura, então o solo é considerado silte argilosos.

De acordo com os dados apresentados na Tabela 2, por meio dos limites de consistências do solo também pode ser classificado conforme o Gráfico de Plasticidade que consta no Manual de Pavimentação do Departamento Nacional de Infraestrutura de Transporte - DNIT, idealizado pelo prefo. Artur Casagrande. Por meio desse gráfico classificamos o material do subleito, como: siltes inorgânicos de baixa compressibilidade.

\begin{tabular}{|c|c|c|c|c|c|c|c|c|c|c|c|}
\hline \multirow{3}{*}{$\begin{array}{c}\begin{array}{c}\text { CLASSIFICACCÃOO } \\
\text { GERAL }\end{array} \\
\begin{array}{c}\text { CLASSIFICAÇÃO EM } \\
\text { GRUPOS }\end{array}\end{array}$} & \multicolumn{7}{|c|}{$\begin{array}{l}\text { MATERIAIS GRANULARES } 35 \% \text { (ou menos) passando na } \\
\text { peneira } N^{0} 200\end{array}$} & \multicolumn{4}{|c|}{ MATERIAIS SILTO - ARGILOSOS } \\
\hline & \multicolumn{2}{|c|}{$A=1$} & \multirow{2}{*}{$A-3$} & \multicolumn{4}{|c|}{ A $=2$} & \multirow{2}{*}{ A. -4} & \multirow{2}{*}{ A -5} & \multirow{2}{*}{ A. -6} & \multirow{2}{*}{$\begin{array}{l}A=7 \\
A=7=5 \\
A=7=6\end{array}$} \\
\hline & $\mid A-1-A$ & $A-1-B$ & & A. - 2-4 & $A-2-5$ & A-2-6 & $|A-2 \cdot 7|$ & & & & \\
\hline \multirow{4}{*}{$\begin{array}{l}\text { Granulometria - \% } \\
\text { passando na peneira } \\
N^{0} 10 \\
N^{0} 40 \\
N^{0} 200 \\
\end{array}$} & \multirow{4}{*}{$\begin{array}{l}50 \text { máx. } \\
30 \text { máx. } \\
15 \text { máx. }\end{array}$} & \multirow{4}{*}{$\begin{array}{l}30 \text { máx. } \\
25 \text { máx. }\end{array}$} & \multirow{4}{*}{$\begin{array}{l}51 \text { min. } \\
10 \text { máx. }\end{array}$} & \multirow[b]{4}{*}{35 máx. } & \multirow[b]{4}{*}{35 máx. } & \multirow[b]{4}{*}{35 máx. } & \multirow[b]{4}{*}{35 máx. } & \multirow[b]{4}{*}{$36 \mathrm{~min}}$. & \multirow[b]{4}{*}{$36 \mathrm{~min}}$. & \multirow[b]{4}{*}{$36 \mathrm{~min}}$. & \multirow[b]{4}{*}{$36 \mathrm{~min}}$. \\
\hline & & & & & & & & & & & \\
\hline & & & & & & & & & & & \\
\hline & & & & & & & & & & & \\
\hline \multicolumn{12}{|l|}{$\begin{array}{l}\text { Caracteristicas da } \\
\text { fraçāo passando na } \\
\text { peneira } N^{\circ} 40 \text { : }\end{array}$} \\
\hline Limite de Liquidez & & & & 40 máx. & $41 \mathrm{~min}$ & 40 máx. & $41 \mathrm{~min}$ & 40 máx. & $41 \mathrm{~min}$. & 40 máx. & $41 \mathrm{~min}$. \\
\hline Indice de Plasticidade & 6 máx. & 6 máx. & NP & 10 máx. & 10 máx. & $11 \mathrm{~min}$ & $11 \mathrm{~min}$ & 10 máx. & 10 máx. & $11 \mathrm{~min}$. & $11 \mathrm{~min} .^{*}$ \\
\hline Indice de Grupo & 0 & 0 & 0 & 0 & 0 & 4 máx. & $4 \max$ & 8 máx. & 12 máx. & 16 máx. & 20 máx. \\
\hline Materiais constituintes & \multicolumn{3}{|c|}{$\begin{array}{l}\text { Fragmentos de pedras, } \\
\text { pedregulho fino e areia }\end{array}$} & \multicolumn{4}{|c|}{$\begin{array}{l}\text { Pedregulho ou areias siltosos ou } \\
\text { argilosos }\end{array}$} & \multicolumn{2}{|c|}{ Solos siltosos } & \multicolumn{2}{|c|}{ Solos argilosos } \\
\hline $\begin{array}{l}\text { Comportamento como } \\
\text { subleito }\end{array}$ & \multicolumn{7}{|c|}{ Excelente a bom } & \multicolumn{4}{|c|}{ Sofrivel a mau } \\
\hline
\end{tabular}

Figura 12: Classificação Highway Research Bord (HRB).

Tabela 2: Caracterização física para a SUCS.

\begin{tabular}{|l|l|c|}
\hline DESCRIÇÃO & RESULTADOS & UN.MED. \\
\hline Massa específica & 2,742 & $(\mathrm{~g} / \mathrm{cm} 3)$ \\
\hline Peneiramento passante na peneira 10 & 100 & $\%$ \\
\hline
\end{tabular}




\begin{tabular}{|l|l|l|}
\hline Peneiramento passante na peneira 40 & 79,1 & $\%$ \\
\hline Peneiramento passante na peneira 200 & 52,9 & $\%$ \\
\hline Limite de liquidez - WL & 29,3 & $\%$ \\
\hline Limite de plasticidade - WP & 21,1 & $\%$ \\
\hline Índice de plasticidade - IP & 8,2 & $\%$ \\
\hline Peso especifico seco máximo- ${ }^{p}$ d máx. & 1,9 & $\mathrm{~g} / \mathrm{cm} 3$ \\
\hline Umidade ótima Wót & 13,2 & $\%$ \\
\hline Coeficiente de uniformidade - CU & 0 \\
\hline Coeficiente de curvatura - CC & 0,0012 \\
\hline
\end{tabular}

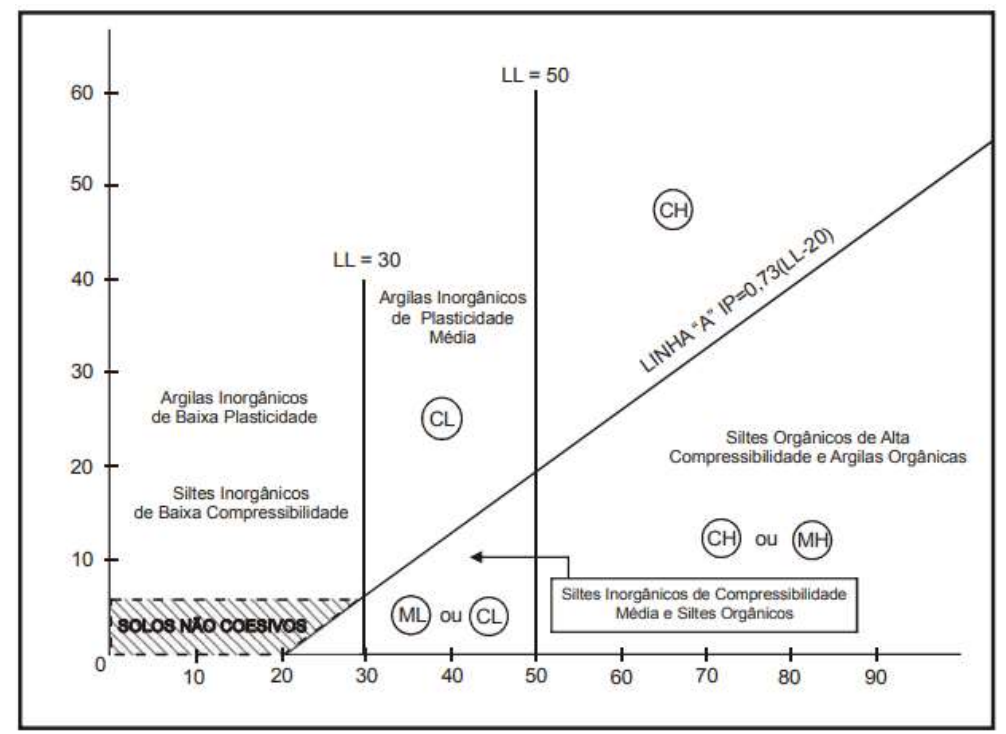

Figura 13: Gráfico de Plasticidade.

De acordo com a NBR 6502/1995 por meio do ensaio de granulometria e sedimentação podemos classificar a quantidade de finos que compõe o solo, sendo $35 \%$ de argila e $15 \%$ de silte, seguidos de $20 \%$, $20 \%$ e $10 \%$ de areia fina, média e grossa, respectivamente, conforme demostrado na Quadro 1.

Quadro 1: Porcentagem de Finos.

\begin{tabular}{|l|l|l|l|l|}
\hline \multicolumn{4}{|l|}{ ABNT NBR 6502/95 } \\
\hline Argila & Silte & Areia & Média 20\% & Grossa 10\% \\
\hline $35 \%$ & $15 \%$ & Fina 20\% &
\end{tabular}

\section{Estimativa de tráfego}

Para este projeto, foi considerado o quantitativo de tráfego anual do Parque Industrial, fornecidos pela empresa de biodiesel, que em sua grande maioria é composto por caminhões pesados. Foi possível, também, conhecer a composição do tráfego, a projeção de tráfego futuro até a final da vida útil da rodovia e o valor de número ' $\mathrm{N}$ ', sendo este o número de repetições de um eixo padrão de 8,2 toneladas durante o período de vida útil da estrutura do pavimento, que foram calculados segundo a metodologia de USACE.

Como mostra nos resultados do Quadro 2, para determinação do número ' $\mathrm{N}$ ' foi considerado a vida útil de projeto de 10 anos, taxa de crescimento de $3 \%$ em conformidade ao projeto de adequação da Marginal Oeste da Rodovia BR-010, região metropolitana do município de Palmas/TO produzido por Costa et al. (2018). O quadro também apresenta, como predomínio os veículos pesados Rodotrem e Romeu e Julieta, sendo também determinado o Volume Médio Diária (VDM) e Fator Veículo (FV). 
Quadro 2: Número 'N'.

\begin{tabular}{|c|c|c|c|c|c|}
\hline \multirow{3}{*}{ ANO } & \multicolumn{2}{|l|}{ VEÍCULO } & \multirow{3}{*}{ VMD } & \multirow{3}{*}{ FV } & \multirow{3}{*}{$\mathbf{N}$} \\
\hline & \multirow{2}{*}{\begin{tabular}{|l|} 
RODOTREM 3 T6 \\
Recebimento de Soja \\
\end{tabular}} & \multirow{2}{*}{$\begin{array}{l}\text { ROMEU E JULIETA } \\
3 \text { C3 } \\
\text { Carregamento de Bio }\end{array}$} & & & \\
\hline & & & & & \\
\hline 2018 & 73 & 13 & 86 & 14631,5916 & $4,58 \mathrm{E}+08$ \\
\hline 2019 & 75 & 13 & 88 & 14631,5916 & $4,72 E+08$ \\
\hline 2020 & 77 & 14 & 91 & 14631,5916 & $4,86 \mathrm{E}+08$ \\
\hline 2021 & 80 & 14 & 94 & 14631,5916 & $5,01 \mathrm{E}+08$ \\
\hline 2022 & 82 & 14 & 97 & 14631,5916 & $5,16 \mathrm{E}+08$ \\
\hline 2023 & 85 & 15 & 99 & 14631,5916 & $5,31 \mathrm{E}+08$ \\
\hline 2024 & 87 & 15 & 102 & 14631,5916 & $5,47 E+08$ \\
\hline 2025 & 90 & 16 & 106 & 14631,5916 & $5,63 E+08$ \\
\hline 2026 & 92 & 16 & 109 & 14631,5916 & $5,80 \mathrm{E}+08$ \\
\hline 2027 & 95 & 17 & 112 & 14631,5916 & $5,98 \mathrm{E}+08$ \\
\hline 2028 & 98 & 17 & 115 & 14631,5916 & $6,16 \mathrm{E}+08$ \\
\hline 2029 & 101 & 18 & 119 & 14631,5916 & $6,34 \mathrm{E}+08$ \\
\hline & & & & Total: & $6,04 \mathrm{E}+09$ \\
\hline
\end{tabular}

Diante o fluxo de tráfego da rodovia, encontrada por meio do número equivalente de operações, definiu-se a espessura mínima do revestimento, que é de $12,5 \mathrm{~cm}$, conforme Figura 14 . Este valor é recomendado para proteção da base contra os impactos gerados pelo tráfego, sendo esforços repetitivos a tração e flexão.

\begin{tabular}{|l|l|}
\hline $\mathrm{N}$ & Espessura mínima de revestimento betuminoso \\
\hline $\mathrm{N} \leq 10^{6}$ & Tratamento superficial com 2,5 a $3,0 \mathrm{~cm}$ de espessura. \\
\hline $10^{6}<\mathrm{N} \leq 5 \times 10^{6}$ & Revestimento betuminosos com $5,0 \mathrm{~cm}$ de espessura \\
\hline $5 \times 10^{6}<\mathrm{N} \leq 10^{7}$ & Concreto betuminosos com $7,5 \mathrm{~cm}$ de espessura \\
\hline $10^{7}<\mathrm{N} \leq 5 \times 10^{7}$ & Concreto betuminosos com $10,0 \mathrm{~cm}$ de espessura \\
\hline $\mathrm{N} \times 5 \times 10^{7}$ & Concreto betuminosos com $12,5 \mathrm{~cm}$ de espessura \\
\hline
\end{tabular}

Figura 14: Espessura Mínima de Revestimento Betuminoso.

Posteriormente, foram encontradas as espessuras das demais camadas que constituem o pavimento, sendo considerado para o dimensionamento o CBR do subleito encontrado no trecho inicial da Avenida Principal do Parque Industrial, devido ser a pior situação. Em seguida foram determinados, a partir do tipo de materiais de que compõem o revestimento, base e sub-base, os coeficientes estruturais. Sendo assim, as camadas de base e sub-base foram dimensionadas como camadas granulares. Os valores dos coeficientes estruturais foram baseados na tabela do DNIT (2006), conforme Figura 15.

\begin{tabular}{|lc|}
\hline \multicolumn{1}{|c|}{ Componentes do pavimento } & Coeficiente $\mathbf{K}$ \\
\hline Base ou revestimento de concreto betuminoso & 2,00 \\
Base ou revestimento pré-misturado a quente, de graduaçăo densa & 1,70 \\
Base ou revestimento pré-misturado a frio, de graduaçăo densa & 1,40 \\
Base ou revestimento betuminoso por penetraçăo & 1,20 \\
\hline \multicolumn{1}{|c|}{ Camadas granulares } & 1,00 \\
\hline $\begin{array}{l}\text { Solo cimento com resistência à compressão } \\
\text { a } 7 \text { dias, superior a } 45 \mathrm{~kg} / \mathrm{cm}\end{array}$ & 1,70 \\
Idem, com resistência à compressão a 7 & 1,40 \\
dias, entre $45 \mathrm{~kg} / \mathrm{cm}$ e $28 \mathrm{~kg} / \mathrm{cm}$ & 1,20 \\
Idem, com resistência à compressão a 7 & \\
dias, entre $28 \mathrm{~kg} / \mathrm{cm}$ e $21 \mathrm{~kg} / \mathrm{cm}$ & \\
\hline
\end{tabular}

Figura 15: Espessura Mínima de Revestimento Betuminoso.

Logo, os coeficientes estruturais adotados nos dimensionamentos, pelo Método do DNER, foram os 
seguintes:

Base Granular $\rightarrow \mathrm{KB}=1,00$

Sub-base Granular $\rightarrow$ KSB $=1,00$

Por fim, foram calculadas as espessuras das demais camadas que constituem o pavimento, foi considerado para o dimensionamento o CBR de subleito encontrado no trecho da Avenida Principal que dá acesso ao pátio industrial de biodiesel, devido ter maior solicitação de esforços no pavimento. Os dados referentes ao trecho em estudo foram os seguintes:

Base $\rightarrow C B R=80,00 \%$

Sub-base $\rightarrow$ CBR $=20 \%$

Subleito $\rightarrow \mathrm{CBR}=38,67 \%$

\section{Espessura do Revestimento (R) - Betuminoso:}

$\mathrm{R}=12,5 \mathrm{~cm}$

\section{Espessura da Camada de Base (B):}

$H t=77,67 * N^{0,0482} * C B R^{-0,598}$

$H 20=77,67 *\left(6,04 * 10^{9}\right)^{0,0482} * 20^{-0,598}$

$H 20=38,34 \mathrm{~cm}$

$R^{*} K r+B * K b>H 20$

$12,5 * 1,2+B * 1>38,34$

$B=23,34 B=24 \mathrm{~cm}$

Espessura da Camada de Sub-Base (Sb):

$H t=77,67 * N^{0,0482} * C B R^{-0,598}$

$H 20=77,67 *\left(6,04^{*} 10^{9}\right)^{0,0482} * 38,67^{-0,598}$

$H 20=25,85 \mathrm{~cm}$

$H 20=26 \mathrm{~cm}$

$R \times K r+B \times K b+H m x k s>H 20$

$12,5 \times 1,2+24 \times 1+H m \times 1>38,34$

$H m=-0,6$

Segundo o Método do DNER, a espessura mínima a ser adotada para camadas granulares deve ser de $15 \mathrm{~cm}$, portanto todos as espessuras adotadas foram as de cálculos. A espessura total da estrutura do pavimento deverá ser de $62,5 \mathrm{~cm}$, conforme Figura 16, sendo suas camadas de $12,5 \mathrm{~cm}, 24 \mathrm{~cm}$ e $26 \mathrm{~cm}$, de revestimento, base e sub-base, respectivamente. 


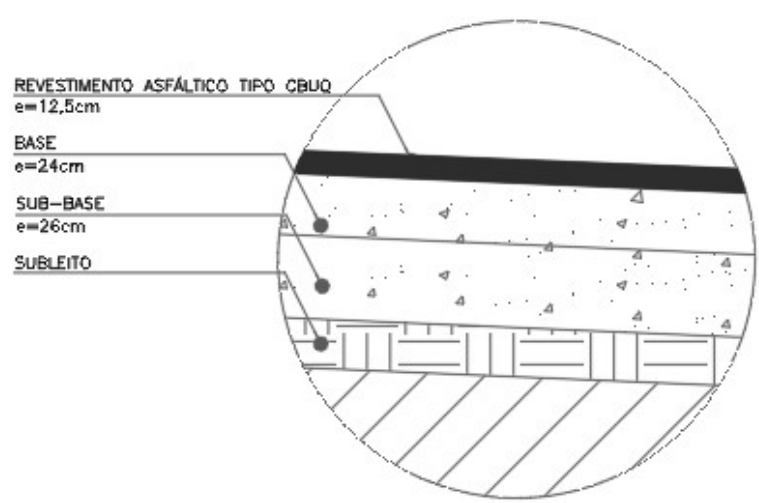

Figura 16: Dimensionamento do pavimento.

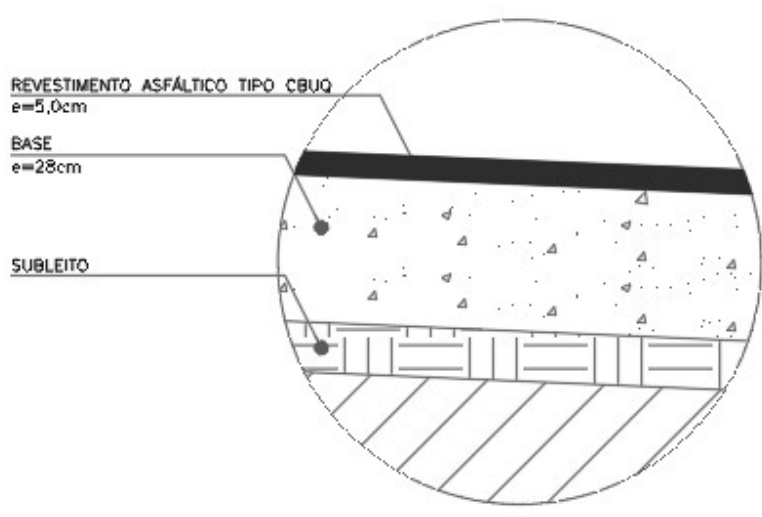

Figura 17: Pavimento atual do pátio da indústria de biodiesel.

De posse do projeto original do pavimento flexível do pátio interno da industrial de biodiesel, que foi disponibilizado pela Granol Industrial, Comércio e Exp., o pavimento destinado a receber o tráfego apresentado neste projeto apresenta espessura do revestimento e base de 5,0, e $28 \mathrm{~cm}$ respectivamente como mostra a Figura 17.

\section{CONCLUSÕES}

A realização deste trabalho possibilitou a determinação do dimensionamento do pavimento a ser construído no Parque Industrial de Porto Nacional - TO. O trecho corresponde a Avenida Principal do parque, extensão de $3 \mathrm{Km}$, que tem seu acesso as margens da rodovia TO-050. A Avenida apresenta uma ineficiência no tráfego diante as patologias existentes, prejudicando assim o transporte de grãos, como a soja cultivada na região, afetando então o agronegócio. $O$ trecho estudado teve sua composição estrutural determinada por ensaios laboratoriais, os quais determinaram CBR dentro dos padrões exigidos pelas normas. Determinou-se dimensões para as camadas de revestimento, base e sub-base, com 12,5, 24 e $26 \mathrm{~cm}$, respectivamente.

Com base nos parâmetros do projeto de pavimentação do pátio da indústria de biodiesel e dos resultados analisados em laboratório, ele não corresponde as especificações mínimas determinada pelo DNIT. Verificou-se que o projeto existente não há uma camada de sub-base, contendo apenas revestimento e base, acima do subleito. Diante aos resultados obtidos, haverá a necessidade de inclusão de uma camada de sub-base, pois não apresentou competência suficiente para resistir aos esforços a que será submetido. Por fim, como sugestão para trabalhos futuros sugere-se que sejam realizados projetos de drenagem da Avenida e Interseção para acesso ao parque.

\section{REFERÊNCIAS}

ABNT. Associação Brasileira de Normas Técnicas. NBR 6508/1984: Grãos de solos que passam na peneira de 4,8 $\mathrm{mm}$ : Determinação da massa específica. Rio de Janeiro: ABNT, 1984.

ABNT. Associação Brasileira de Normas Técnicas. NBR 7180/1982: Determinação do Limite de Plasticidade. Rio de
Janeiro: ABNT, 1982

ABNT. Associação Brasileira de Normas Técnicas. NBR 6502/1995: Solo: Análise Granulométrica. Rio de Janeiro: ABNT, 1995.

ABNT. Associação Brasileira de Normas Técnicas. NBR 
7182/1988: Solo: Ensaio de Compactação. Rio de Janeiro: ABNT, 1988.

ABNT. Associação Brasileira de Normas Técnicas. NBR 9895/2017: Solo: Índice de suporte Califórnia (ISC): Método de ensaio. Rio de Janeiro: ABNT, 2017.

COSTA, T. S.; SILVA JÚNIOR, F. V.. Pavimentos flexíveis: estudo de caso da marginal oeste da rodovia BR-010, região metropolitana do município de Palmas/TO. Engineering
Sciences, v.6, n.2, p.43-52, 2018. DOI:

http://doi.org/10.6008/CBPC2318-3055.2018.002.0005

DNIT. Departamento Nacional de Infraestrutura de Transporte. Manual De Pavimentação. Publicação IPR-719. 3 ed. Rio de Janeiro: DNIT, 2006.

PORTER, M. E.. A vantagem competitiva das nações. 14 ed Rio de Janeiro: Campus, 1989.

A CBPC - Companhia Brasileira de Produção Científica (CNPJ: 11.221.422/0001-03) detém os direitos materiais desta publicação. Os direitos referem-se à publicação do trabalho em qualquer parte do mundo, incluindo os direitos às renovações, expansões e disseminações da contribuição, bem como outros direitos subsidiários. Todos os trabalhos publicados eletronicamente poderão posteriormente ser publicados em coletâneas impressas sob coordenação da Sustenere Publishing, da Companhia Brasileira de Produção Científica e seus parceiros autorizados. Os (as) autores (as) preservam os direitos autorais, mas não têm permissão para a publicação da contribuição em outro meio, impresso ou digital, em português ou em tradução. 